\title{
Simultaneous Determination of Catechol and Hydroquinone Using Nickel Nanoparticles $\backslash$ Poly-4-Nitroaniline Nanocomposite Modified Glassy Carbon Electrode
}

\author{
Chedia Ben Ali Hassine ${ }^{\circledR}$, Hamza Kahri ${ }^{\circledR}$, and Houcine Barhoumi
}

\begin{abstract}
In this paper, a simple procedure has been developed to fabricate sensor based on Ni nanoparticles and poly4-nitroaniline (P4NA) modified glassy carbon electrode (GCE) for simultaneous detection of catechol and hydroquinone. The formed composite film was characterized by scanning electron microscopy (SEM), UV-visible spectroscopy, electrochemical impedance spectroscopy (EIS) and DPV measurements. The modified electrode showed high sensitivity and selectivity towards catechol (CC) and hydroquinone (HQ). Under optimized conditions, the modified GCE showed two sharp redox peaks for $C C$ and $H Q$ in differential pulse voltammetry (DPV) voltammograms with a peak potential separation of $112 \mathrm{mV}$ in $\mathrm{pH} 7.0$ phosphate buffer solution (PBS). The

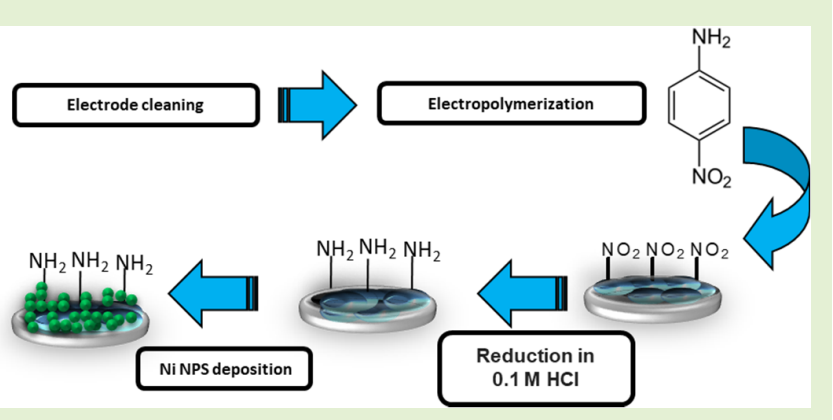
detection limits for $H Q$ and $C C$ were calculated to be 2.3 and $3.9 \mu M$, respectively. Good linearity was observed for a concentration range from $10^{-9}-10^{-4} \mathrm{M}$ and $10^{-3}-10^{-4} \mathrm{M}$ for $\mathrm{CC}$ and $\mathrm{HQ}$ respectively. Furthermore, the newly made electrode was successfully evaluated in the detection of both analytes $C C$ and $\mathrm{HQ}$ in seawater as a real sample.
\end{abstract}

Index Terms-Glassy carbon electrode, hydroquinone, 4-nitroanoline, catechol, electrochemical measurement.

\section{INTRODUCTION}

C ATECHOL (CC) and hydroquinone (HQ) are two isomers of dihydroxybenzene. These phenolic compounds are used in dye production, medicine, photostabilizers, cosmetics and pesticides [1], [2]. Dihydroxybenzene isomers are extensively dispersed due to their variety sources and are considered as important environmental pollutants because of their toxicity and low degradability in the environment [3].

Manuscript received March 16, 2021; revised June 7, 2021; accepted June 10, 2021. Date of publication June 14, 2021; date of current version August 31, 2021. This work was supported by the PRF-2017D4P1/Tunisia Project under Grant $12 \mathrm{Mag} 088$ and in part by the Ministry of Higher Education and Scientific Research of Tunisia under Grant LR11ES55. The associate editor coordinating the review of this article and approving it for publication was Prof. Venkat R. Bhethanabotla. (Corresponding author: Hamza Kahri.)

Chedia Ben Ali Hassine and Houcine Barhoumi are with the Laboratory of Interfaces and Advanced Materials, Faculty of Sciences, University of Monastir, Monastir 5000, Tunisia (e-mail: bchedia@yahoo.fr; houcine.barhoumi@fsm.rnu.tn).

Hamza Kahri is with the Laboratory of Interfaces and Advanced Materials, Faculty of Sciences, University of Monastir, Monastir 5000, Tunisia, and also with the Department of Chemistry, Faculty of Science, Bilkent University, 06800 Ankara, Turkey (e-mail: hamza.kahri@bilkent.edu.tr).

Digital Object Identifier 10.1109/JSEN.2021.3089249
For those reasons, the determination of hydroxybenzenes has become one of the important topics for environmental analysis. Phenolic compounds measurement is generally carried out using liquid chromatography [4], spectrophotometry [5], and electrochemiluminescence 6 . However, these methods lack selectivity [7]. In this context, electrochemical sensors represent an appropriate alternative for a fast, reliable, cost-effective and in-situ analysis. Sensors using glassy carbon or carbon paste electrodes for direct electrochemical detection have been reported in literature [8]. However, due to the similar structure of $\mathrm{CC}$ and $\mathrm{HQ}$, the use of conventional electrodes such as glassy carbon electrodes is difficult considering the possible overlap of their redox potentials. To overcome this problem, various kinds of composites based on conducting polymers (CP) and nanoparticles (NPs) have been developed. The modification of the glassy carbon electrode using NPs and $\mathrm{CP}$ can enhance the surface area, provide a good electron transfer capability and decrease over-potential [9]-[14]. Recently, several authors have published papers on the detection of $\mathrm{CC}$ and HQ using nanocomposites based on precious metals like Pt, Au and Pd [15]-[17]. However, cheaper nanoparticles based on transitions metals are still needed. Ni nanoparticles 
are one of the most extensively used materials for many sensors due to their unique properties such as good electron transfer and large surface area [18]. In the recent years, considerable efforts have been made to develop magnetic nanoparticles like $\mathrm{Ni}$, due to their various advantages such as different shapes and sizes, physicochemical properties and low cost of production. In addition, magnetic nanoparticles have been used to improve the sensitivity and the stability of sensors and biosensors for the detection of multiple analytes for clinical, environmental and food applications [19]-[33]. According to our knowledge, this is the first time that an electrochemically prepared sensor based on $\mathrm{Ni}$ nanoparticle modified poly-4-nitroaniline film glassy carbon electrode is used for the simultaneous detection of $\mathrm{CC}$ and HQ.

\section{Material AND Methods}

\section{A. Chemicals}

4-nitroaniline, Tetra-n-butylammoniumtetrafluoroborate and acetonitrile were purchased from Merck. $\mathrm{KCl}$ (potassium chloride) was purchased from PROLABO. Catechol, hydroquinone and $\mathrm{NiSO}_{4}$ were purchased from Sigma Aldrich. Ferricyanide $\left(\mathrm{K}_{4} \mathrm{Fe}(\mathrm{CN})_{6}\right)$, ferrocyanide $\left(\mathrm{K}_{3} \mathrm{Fe}(\mathrm{CN})_{6}\right)$, Potassium monohydrogenphosphate $\left(\mathrm{K}_{2} \mathrm{HPO}_{4}\right)$ and Potassium dihydrogen phosphate were purchased from Fluka. Aqueous solutions were prepared using deionised water.

\section{B. Apparatus}

A traditional three-electrode cell system was used in all electrochemical experiments. A platinum wire was used as a counter electrode and GC electrodes were used as working electrodes with a geometric area of $0.07 \mathrm{~cm}^{2}$. The used reference electrode is $\mathrm{Ag} / \mathrm{AgCl}$ in saturated $\mathrm{KCl}$ $(\mathrm{Ag} / \mathrm{AgCl} /($ sat. $\mathrm{KCl}))$ in aqueous media and an $\mathrm{Ag} / \mathrm{Ag}^{+}$ (in $10 \mathrm{mM} \mathrm{AgNO}_{3}$ ) was used in non-aqueous media. The electrochemical experiments were carried out using a potentiostat (DY200 POT Eco-chemie) for cyclic voltammetry (CV) and an Autolab PGSTAT 320N potentiostat for impedance spectroscopy spectra measurements controlled by computer with software (NOVA 1.5) for data analysis. For impedance measurements, all experiments were carried out inside a Faraday cage. UV-visible absorbance spectra were recorded with a 67 series JENWAY spectrophotometer Model 6705.

\section{Electrode Modification}

The surface of the GC electrode was polished with $10 \mu \mathrm{m}$ alumina-water slurry using a polishing cloth. Before the deposition, the electrode is placed in an ultrasonic bath in a solution (1V / $1 \mathrm{~V})$ of acetonitrile / isopropyl alcohol in order to remove any particles that may be on the surface of the electrode. The modification of the glassy carbon electrode (GCE) was carried out by cyclic voltammetry in an electrochemical cell containing $1 \mathrm{mM}$ 4-nitroaniline and $100 \mathrm{mM}$ tetrabutylammonium tetrafluoroborate (TBATFB) as a carrier electrolyte dissolved in acetonitrile $\left(\mathrm{CH}_{3} \mathrm{CN}\right)$. The reference electrode used is an $\mathrm{Ag} / \mathrm{Ag}^{+} / \mathrm{AgNO}_{3}$ electrode $(10 \mathrm{mM})$ at a scanning rate of $0.1 \mathrm{~V} / \mathrm{s}$. Following our previous

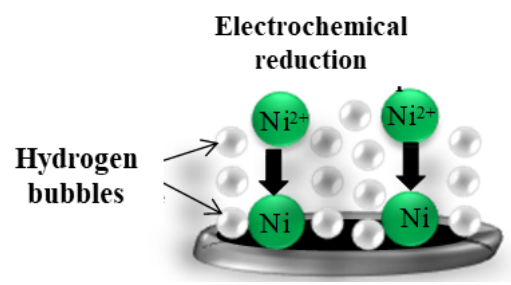

Fig. 1. Schematic illustration of Ni nanoparticles deposition.

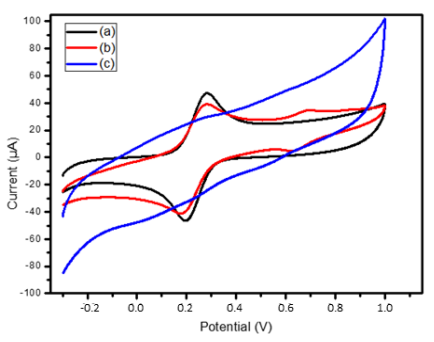

Fig. 2. Cyclic voltammograms of GCE. (a) Bare, (b) P-4NA-red and (c) P-4NA-red_Ni(NPs) in the presence of $[\mathrm{Fe}(\mathrm{CN}) 6]^{3-/ 4-}\left(10^{-3} \mathrm{M}\right)$, $\mathrm{KCl}(0.1 \mathrm{M}) \mathrm{V}=0.1 \mathrm{~V} / \mathrm{s}, \mathrm{pH}=7$.

work [34], the glassy carbon electrode was modified by cyclic voltammograms for 50 cycles for poly-4-nitroaniline deposition. After the deposition of the polymer, the surface of the electrode was rinsed with deionized water. Then, the electrochemical reduction of the nitro groups on the surface of the glassy carbon electrode into amine groups was done by cyclic voltammetry in an aqueous solution of hydrochloric acid $(100 \mathrm{mM})$ in a potential range from $-0.1 \mathrm{~V}$ to $-0.8 \mathrm{~V}$ at a scanning speed of $0.1 \mathrm{~V} / \mathrm{s}$ [35]. After rinsing with deionized water and drying at room temperature, the pre-treated electrode was immersed in a $0.2 \mathrm{M} \mathrm{NiSO}_{4}$ solution containing $1 \mathrm{M}$ $\mathrm{H}_{2} \mathrm{SO}_{4}$ for 15 minutes. An electrodeposition process with a constant current of 0.1 A was carried out. During the electroreduction of $\mathrm{Ni}^{2+}$, continuous formation of hydrogen occurred, which caused the appearance of air bubbles on the electrode surface [36] (Figure 1). Finally, the resulting electrode was thoroughly rinsed with ultrapure water and air dried for better characterization and electrochemical measurements.

\section{Results AND Discussions}

\section{A. Electrode Characterization}

1) Cyclic Voltammetry: In order to characterize the formation of the poly-4-nitroaniline-Ni NPs layer on the surface of the GC electrode, the cyclic voltammograms were recorded in a redox probe (ferrocyanide) as shown in the Figures 2. The oxidation peak potential differences in the cyclic voltammograms are 85, $105 \mathrm{mV}$ at bare GC and P-4NA-RED electrodes, respectively. It is noticeable in Figure 2 for the P-4NA-RED-Ni (NPs) that the oxidation and reduction peaks are not observable. This may be due to repulsion between the deposited P-4NA-RED-Ni (NPs) layer and ferrocyanide. This repulsion is probably due to the nanoparticles of $\mathrm{Ni}$ that can undergo a delocalization of their charges causing a partially negative cloud effect. The active surface area was calculated using Randles-Sevcik equation [46]. The calculated 


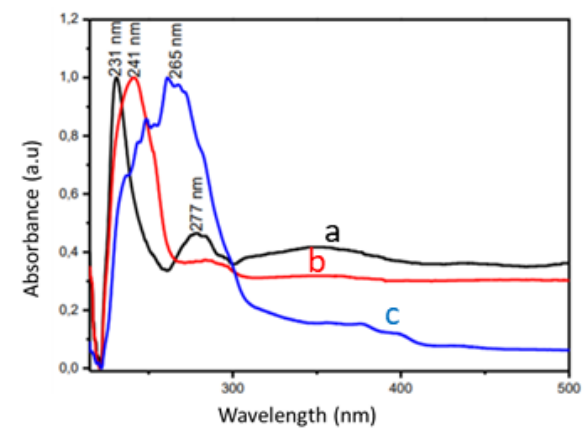

Fig. 3. Absorbance curves of (a) P-4NA, (b) P-4NA-red and (c) P-4NAred-Ni(NPs) in dichloromethane.

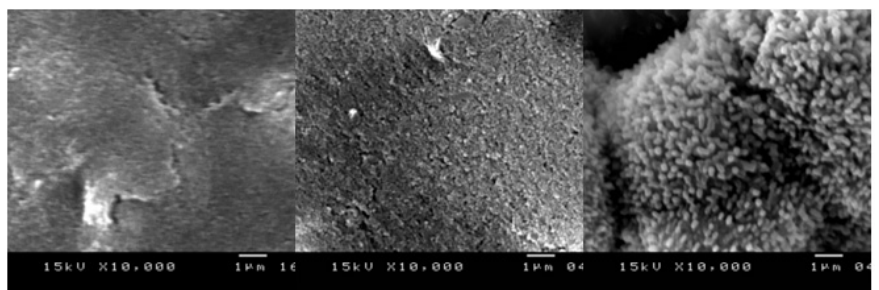

(a)

(b)

(c)

Fig. 4. Scanning electron micrographs, (a) bare screen-printed carbon electrode (SPCE), (b) SPCE/P4NA-red and (c) SPCE P4NA-RED/Ni (NPs). Resolution of $1 \mu \mathrm{m}$, magnification of $200 \times$ and 10.000 and accelerating potential of $15.0 \mathrm{kV}$ were used.

electroactive surfaces are as follow: the GC electrode is $0.1038 \mathrm{~cm}^{2}$, the GC/P-4NA-RED is $0.00502 \mathrm{~cm}^{2}$ and for the GC/P-4NA-RED-Ni (NPs) is $0.00525 \mathrm{~cm}^{2}$. The calculation of the electroactive surface of the electrode shows a decrease in its value after the electrode modification. We observed a decrease in the current in the presence of negatively charged ferrocyanide after the deposition of Ni nanoparticles in comparison to the electrode modified with poly-4-nitroaniline. (Figure 2).

2) UV Visible: The UV-visible absorption spectra of P-4NA, P-4NA-RED and P-4NA-RED-Ni (NPs) recorded at room temperature are given in Figure 3. The different layers were synthesized on the electrodes using the same conditions described above and then dissolved in dichloromethane. Figure 3 (a) shows that 2 distinct bands of P-4NA appear at $230 \mathrm{~nm}$ and $278 \mathrm{~nm}$ [37], [38]. The first band is assigned to the $\pi \rightarrow \pi^{*}$ transition of the benzenoid ring. The second absorption band is attributed to the $\mathbf{n} \rightarrow \boldsymbol{\pi}^{*}$ which corresponding to the unshared pair of nitro groups. In Figure 3 (b), it can be seen that the $278 \mathrm{~nm}$ band disappeared which confirm the reduction of nitro to amino groups and the band at about $230 \mathrm{~nm}$ was shifted to $240 \mathrm{~nm}$. In Figure 3 (c), corresponding to P-4NA-red-Ni (NPs), a band appears at $265 \mathrm{~nm}$ and can be explained by the incorporation of $\mathrm{Ni}$ into the polymeric layer.

3) SEM Characterization: Surface morphologies of bare screen-printed carbon electrode (SPCE), P-4NA-RED $\backslash$ SPCE and P-4NA-RED-Ni (NPs) $\backslash$ SPCE were investigated with SEM. SEM images of P-4NA-RED $\backslash$ SPCE and P-4NARED-Ni (NPs) \SPCE, shown in Figure (4), were used to explore the difference in term of surface coverage with and

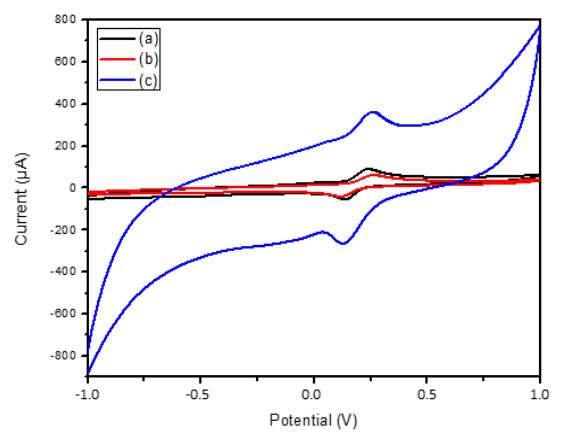

Fig. 5. Cyclic voltammograms of (a) bare GCE, (b) GCE / P4NA-red and (c) GCE / P-4NA-red_Ni (NPs) in $10^{-3} \mathrm{M}$ catechol (PBS pH =7) $100 \mathrm{mV} / \mathrm{s}$.

without Ni NPs. Flat and smooth surface covering P-4NARED $\backslash$ SPCE was twisted to form spherical particles with a narrow particle size distribution and an average particle size of $0.12 \pm 0.03 \mu \mathrm{m}$ The P-4NA-RED could not be observed with SEM but after the Ni nanoparticles deposition we can clearly see the incorporation of the $\mathrm{Ni}$ nanoparticles to the film. The nanoparticles provide high electronic conductivity with making the surface of the electrode larger. It should be also notified that the deposited thin film is mechanically stable and adhere strongly to the electrode surface and does not leach out only after polishing the electrode.

4) Catechol Detection: The electrochemical behaviour of the modified electrodes was tested by cyclic voltammetry and electrochemical impedance in the presence of catechol (CC). The results are summarized in Figures 5. A significant increase in the current is observed after the deposition of nickel nanoparticles. A reversible catechol peak is observed for all the electrodes with a smaller value of $\Delta \mathrm{E}$ for the P-4NA-red-Ni electrode (NPs). This proves that nickel increases the charge transfer at the surface of the electrode. The difference potential for the bare GCE, (b) GCE / P4NA-red and (c) GCE / P-4NA-red Ni (NPs) are respectively 130, 140 and $117 \mathrm{mV}$. A higher anodic peak is observed for the GCE / P-4NA-red-Ni (NPs) equal to $366 \mu \mathrm{A}$ if we compare it to the bare and P4NA-red electrodes. These results confirm the affinity of the modified electrode for catechol. Also, impedance measurements were carried out and the obtained nyquist diagrams are shown in the Figure 6. The equivalent circuit includes the solution resistance (Rs), the charge transfer resistance $(\mathrm{RCt})$, the Warburg resistance (Wo) and the constant phase element (CPE). It can be noticed that for the electrode modified with nickel the semicircle of nyquist is not significant, however, a straight line is observed and represents the diffusion process of catechol molecules present in the electrochemical cell. These results confirm the affinity of our modified electrode toward catechol molecules.

5) Study of the Effect of $\mathrm{pH}$ and lonic Strength of the Electrolyte: The electrolyte's $\mathrm{pH}$ effect on the electrochemical response has been studied. Different PBS solutions were prepared at $\mathrm{pH}$ values ranging from 4 to 12 . Figure 7 shows the results obtained. It can be concluded that the intensity of the current varies according to the $\mathrm{pH}$, the anodic peak 


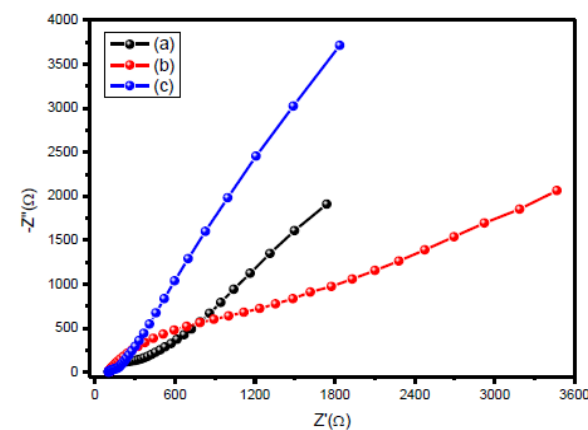

Fig. 6. Nyquist plot (a) bare GCE, (b) GCE / P4NA-red and (c) GCE / P-4NA-red_Ni (NPs) in $10^{-3} \mathrm{M}$ catechol (PBS pH $=7$ ).

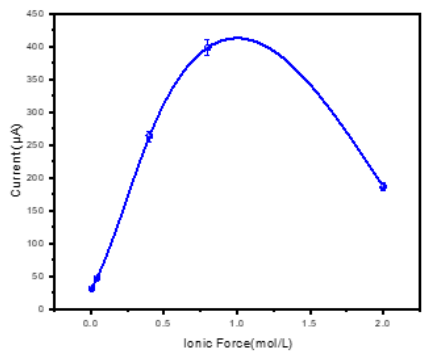

Fig. 7. The effect of the $\mathrm{pH}$ of the solution on the oxidation potential of CC.

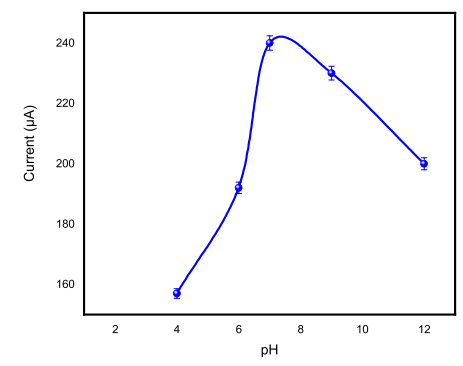

Fig. 8. The effect of the ionic strength of the solution on the detection of $\mathrm{CC}$ at $\mathrm{pH} 7$.

current reaches a maximum at $\mathrm{pH} 7$ and then decreases at $\mathrm{pH}$ values higher than 7 . Which is in agreement with the results previously obtained for the detection of different types of phenols [11]. Therefore, a phosphate buffer with a $\mathrm{pH}$ value of 7 was selected for all other experiments. Then, the effect of the ionic strength was studied by varying the concentration of the buffer from 0.001 to $0.5 \mathrm{M}$ at $\mathrm{pH} 7$ as shown in Figure 8 . In Figure 8, an increase of the anode current is observed with the increase of the ionic strength up to $\mathrm{I}=1$ and then a considerable decrease of the current is observed.

Therefore, the $0.1 \mathrm{M}$ concentration was used for subsequent experiments.

6) Differential Pulse Voltammetry: Differential pulse voltammetry (DPV) was used to test the sensitivity of the developed electrode to catechol (Figure 9). The parameters used were optimized before recording the spectra. With an amplitude of $50 \mathrm{mV}$, a potential step of $5 \mathrm{mV}$ and a sensitivity of $10^{-3} \mathrm{~A} / \mathrm{V}$. Catechol detection was performed to confirm the analytical performance of the deposited composite (a)

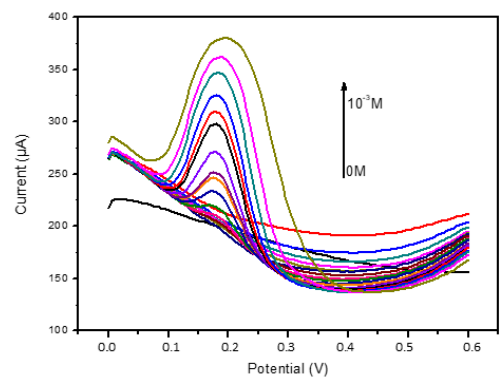

(b)

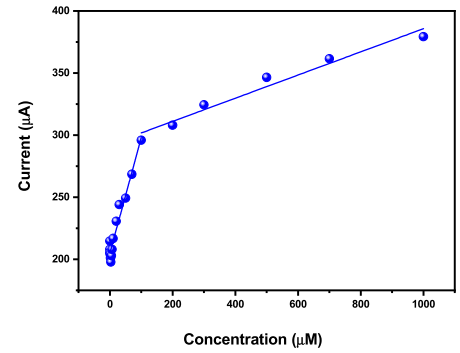

Fig. 9. (a) DPV and (b) calibration curve for catechol detection with modified electrode in a PBs solution $(0.1 \mathrm{M})$ at $\mathrm{pH}=7$.

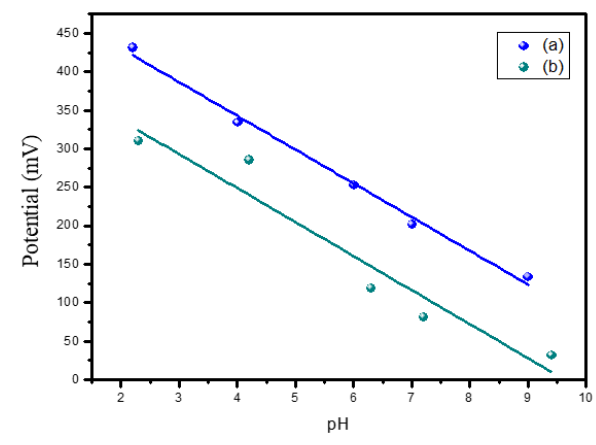

Fig. 10. pH Effect on the oxidation potential of (a) $\mathrm{CC}$ and (b) HQ.

film (P-4NA-red-Ni (NPs)). At the concentration range of $10^{-2}-100$ and $100-1000 \mu \mathrm{mol} \cdot \mathrm{L}^{-1}$, the current response signal (I) was proportional to the concentration (c) of CC. The linear regression equations were as follows: $\mathrm{I}=0.9279 \mathrm{c}+2.05 \times$ $10^{-4} \mathrm{~A}$ and $\mathrm{I}=0.0932 \mathrm{c}+2.92 \times 10^{-4} \mathrm{~A}$. It can be concluded that the electrode modified using poly-4-nitroaniline composite and $\mathrm{Ni}$ nanoparticles has satisfying analytical performances. This may be due to the effect of Ni nanoparticles that facilitate the electronic transfer across the surface of the modified electrode. This can increase the intensity of the oxidation current for the CV/P-4NA-red-Ni electrode (NPs).

7) Effect of $\mathrm{pH}$ on the Oxidation Potential of $\mathrm{CC}$ and $H Q$ : The effect of the solution's $\mathrm{pH}$ on the oxidation potential of CC and HQ was studied in the range of 2 to 9. Indeed, the separation between the two peaks is a significant parameter in the simultaneous detection. The relation between $\mathrm{pH}$ and 


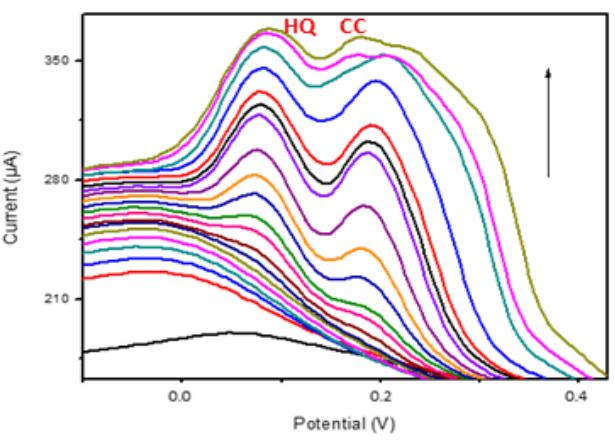

Fig. 11. DPV for the detection of hydroquinone and catechol using GCE / P-4NA-red-Ni (NPs) electrode in PBS solution (0.1M) at $\mathrm{pH}=7$.

anode peak potential is illustrated in Figure 10. It can be seen that the potentials of the anodic peaks decrease with increasing $\mathrm{pH}$ for $\mathrm{CC}$ and $\mathrm{HQ}$. The two regression lines are nearly parallel, implying that the peak-to-peak separation between CC and $\mathrm{HQ}$ is constant at different $\mathrm{pH}$ values. The slopes of these equations have been calculated. The linear regression lines are expressed by equations 1 and 2 for CC and HQ respectively.

(1) $\mathrm{E}_{\mathrm{pa}}=0,5184+(-0,04384) \times \mathrm{pH}\left(\mathrm{R}^{2}=0.991\right)$

(2) $\mathrm{E}_{\mathrm{pb}}=0,42591+(-0,04419) \times \mathrm{pH}\left(\mathrm{R}^{2}=0.911\right)$

where Ep is the potential of the anodic peak and $\mathrm{R}$ is a correlation coefficient. The calculated slopes are close to the theoretical value of $59 \mathrm{mV} / \mathrm{pH}$ ( 43 and $44 \mathrm{mV}$ ), suggesting that the redox reaction of $\mathrm{CC}$ (or HQ) at the interface of the electrode should be a process involving two electrons and two protons. Therefore, in order to achieve a high sensitivity, $\mathrm{pH} 7.0$ was chosen for the simultaneous determination of CC and HQ.

8) Simultaneous Detection of CC and HQ: The excellent electrocatalytic activity of the modified electrode promises a simultaneous selective determination of HQ and CC. The electrochemical behaviour of the modified electrode in a solution containing both $\mathrm{HQ}$ and $\mathrm{CC}$ was studied using differential pulse voltammetry. Figure 10 shows the DPV responses vs. the change in HQ and CC concentrations in $0.1 \mathrm{M}$ PBS (pH 7.0). Two distinguishable peaks are observed at potential levels of $+0.089 \mathrm{~V}$ and $+0.201 \mathrm{~V}(\Delta \mathrm{E}=112 \mathrm{mV})$. Which correspond to the respective redox process of $\mathrm{HQ}$ and $\mathrm{CC}$ on the modified electrode. This distinction of the oxidation potential of $\mathrm{CC}$ and HQ is promising of a good electrode sensitivity 40 . The results showed that the intensity of the anodic current is proportional to the concentrations of $\mathrm{HQ}$ and $\mathrm{CC}$ indicating that the oxidation of CC and HQ to the electrode takes place independently (Figure 11). The following Table I summarizes the analytical performance of the sensor developed for simultaneous and individual detection of CC and HQ. A slight decrease in sensitivity is observed for hydroquinone detection. The results obtained in this work are compared with different modified electrodes for determination of $\mathrm{CC}$ and HQ. The linear range and detection limit are gathered in Table II. From the Table II, it can be seen that the proposed method shows a large linear range and acceptable detection limit compared to previous papers where metallic composites have not been used [12], [45].
TABLE I

Analytical Performances of the Sensor DeVeloped for SIMULTANEOUS AND INDIVIDUAL DETECTION OF CC AND HQ

\begin{tabular}{|c|c|c|c|c|}
\hline Analytes & $\begin{array}{c}\text { Linear } \\
\text { range (M) }\end{array}$ & $\begin{array}{c}\text { LOD } \\
\text { (M) }\end{array}$ & $\begin{array}{c}\text { Sensitivity } \\
\text { (A/M) }\end{array}$ & $R^{2}$ \\
\hline $\mathrm{CC}$ & $\begin{array}{c}10^{-9}-10^{-4} \\
\text { and } 10^{-3}-10^{-4}\end{array}$ & $2.3 \underset{6}{\times 10^{-}}$ & $\begin{array}{l}0.9279 \\
0.0932\end{array}$ & $\begin{array}{l}0.9690 \\
0.9757\end{array}$ \\
\hline HQ & $\begin{array}{c}10^{-9}-10^{-4} \\
\text { and } 10^{-3}-10^{-4}\end{array}$ & $3,9 \times 10^{-6}$ & 0.8925 & 0.9689 \\
\hline \multirow{2}{*}{$\begin{array}{c}\mathrm{CC} \text { and } \\
\mathrm{HQ}\end{array}$} & $\begin{array}{l}\text { CC } 10^{-9}-10^{-4} \\
\text { and } 10^{-3}-10^{-4}\end{array}$ & $3.8 \underset{6}{\times 10^{-}}$ & 0.9799 & 0.9707 \\
\hline & $\begin{array}{l}\text { HQ } 10^{-9}-10^{-4} \\
\text { and } 10^{-3}-10^{-4}\end{array}$ & $2.5 \underset{6}{5} \times 10^{-}$ & 0.8405 & 0.9832 \\
\hline
\end{tabular}

TABLE ॥

Analytical Performance of Sensors Reported in the LITERATURE FOR THE DETECTION OF CC AND HQ

\begin{tabular}{|c|c|c|c|}
\hline Modified electrode & LOD $(\mu \mathrm{M})$ & $\begin{array}{l}\text { Linear range } \\
\quad(\mu \mathrm{M})\end{array}$ & Ref. \\
\hline \multirow{2}{*}{ Graphene/GCE } & CC 0.01 & $1-50$ & \multirow{2}{*}{41} \\
\hline & HQ 0.015 & $1-50$ & \\
\hline \multirow{2}{*}{$\mathrm{NiO} / \mathrm{CNT} / \mathrm{GCE}$} & CC 1.0 & $5-80$ & \multirow{2}{*}{42} \\
\hline & HQ 2.3 & $10-120$ & \\
\hline \multirow{2}{*}{$\mathrm{Au}-\mathrm{PdNF} / \mathrm{rGO} / \mathrm{GCE}$} & $\mathrm{CC} 2$ & $2.5-100$ & \multirow{2}{*}{43} \\
\hline & HQ 1 & $1.6-100$ & \\
\hline \multirow{2}{*}{ AuNPs-MPS/CPE } & CC 1.2 & $10-1000$ & \multirow{2}{*}{44} \\
\hline & HQ 1.1 & $30-1000$ & \\
\hline \multirow{2}{*}{ Au@Pd/rGO } & CC 0.1 & $0.1-400$ & \multirow{2}{*}{45} \\
\hline & $\mathrm{HQ} 0.01$ & $0.01-400$ & \\
\hline \multirow{2}{*}{ CNF- AuNPs } & CC 0.86 & $9-500$ & \multirow{2}{*}{46} \\
\hline & $\mathrm{HQ} 0.36$ & $5-350$ & \\
\hline \multirow{2}{*}{ Activated GCE } & CC 0.11 & $0.5-200$ & \multirow{2}{*}{47} \\
\hline & HQ 0.16 & $0.5-200$ & \\
\hline \multirow{2}{*}{ MWCNT/GCE } & CC 0.75 & $1-100$ & \multirow{2}{*}{48} \\
\hline & HQ 0.2 & $0.6-100$ & \\
\hline \multirow{2}{*}{$\begin{array}{l}\text { Organic framework modified } \\
\text { carbon paste electrode }\end{array}$} & CC 0.46 & $1-2000$ & \multirow{2}{*}{50} \\
\hline & HQ 0.31 & $1-2000$ & \\
\hline \multirow{2}{*}{ NCNTFs/GCE } & CC 0.12 & $0.8-40$ & \multirow{2}{*}{51} \\
\hline & HQ 0.17 & 100 to 200 & \\
\hline Pd/Poly(TAU)/GCE & $\begin{array}{c}C C \\
0.00068 \\
H Q 0.0021\end{array}$ & $\begin{array}{l}0.008-100 \\
0.001-100\end{array}$ & 52 \\
\hline Ox-PRT/GCE & $\begin{array}{r}\text { CC } 0.031 \\
\text { HQ } 0.053\end{array}$ & $\begin{array}{c}0.06-3.5,8-55 \\
0.06-3.5,8-55\end{array}$ & 53 \\
\hline Pt/Poly(Isoleucine)/GCE) & $\begin{array}{l}\mathrm{CC} 0.005 \\
\mathrm{HQ} 0.006 \\
\end{array}$ & $\begin{array}{l}0.01-100 \\
0.01-100 .\end{array}$ & 54 \\
\hline \multirow{2}{*}{ P-4NA-RED/Ni(NPs)/GCE } & CC 3.9 & $\begin{array}{c}10^{-3}-100 \\
\text { and } 100-1000\end{array}$ & \multirow{2}{*}{$\begin{array}{l}\text { This } \\
\text { work }\end{array}$} \\
\hline & HQ 2.3 & $\begin{array}{c}10^{-3}-100 \\
\text { and } 100-1000\end{array}$ & \\
\hline
\end{tabular}

NCNTFs: N-doped carbon nanotube frameworks

$\mathrm{NF} / \mathrm{rGO}$ : nanoflower/reduced graphene oxide nanocomposite

CNT:carbon nanotube

CNF:carbonnanofibers

MPS: Mesoporous Silica

Ox-PRT: over-oxidized poly(Rutin)

9) Study of Interference: In this section, we have studied the interference of other species on the detection of catechol and hydroquinone in order to test the selectivity of the prepared electrode. The results obtained are summarized in Figure 12. 


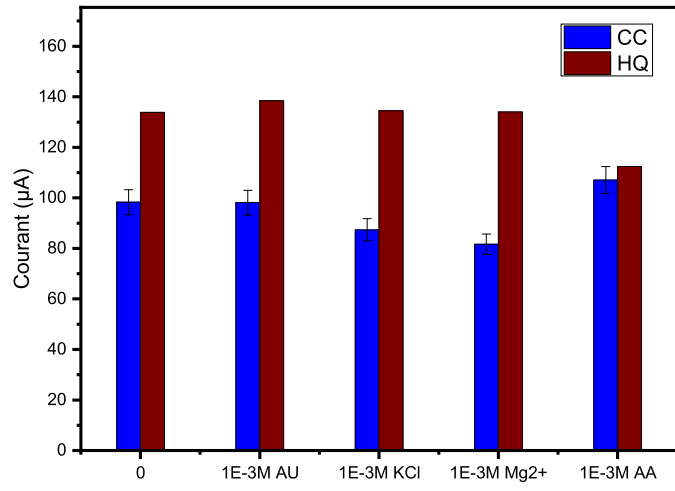

Fig. 12. Interference study in PBS $0.1 \mathrm{M} \mathrm{pH}=7$.

TABLE III

RECOVERY OF CC AND HQ IN SEAWATER

\begin{tabular}{|c|c|c|c|c|}
\hline \multirow{3}{*}{$\begin{array}{c}\text { Samples } \\
1\end{array}$} & \multirow{3}{*}{$\begin{array}{c}\begin{array}{c}\text { Added } \\
\text { concentration } \\
(\boldsymbol{\mu m o l} / \mathrm{L})\end{array} \\
1 \\
1\end{array}$} & \multicolumn{2}{|c|}{$\begin{array}{c}\text { Measured } \\
\text { concentration } \\
(\mu \mathrm{mol} / \mathrm{L})\end{array}$} & \multirow{2}{*}{$\begin{array}{c}\begin{array}{c}\text { Recovery } \\
\%\end{array} \\
120 \\
\end{array}$} \\
\hline & & $\mathrm{CC}$ & 1.2 & \\
\hline & & HQ & 1.1 & 110 \\
\hline \multirow[b]{2}{*}{2} & \multirow[b]{2}{*}{10} & $\mathrm{CC}$ & 10.9 & 109 \\
\hline & & HQ & 16 & 120 \\
\hline \multirow[b]{2}{*}{3} & \multirow[b]{2}{*}{50} & $\mathrm{CC}$ & 61 & 122 \\
\hline & & HQ & 45 & 90 \\
\hline \multirow[b]{2}{*}{4} & \multirow[b]{2}{*}{100} & $\mathrm{CC}$ & 150 & 150 \\
\hline & & HQ & 120 & 120 \\
\hline
\end{tabular}

It is necessary to note that there is a negligible variation in the peak intensity in the presence of interfering substances, which was 100-folds higher than that of CC and HQ. Moreover, according to the literature, researchers have studied resorcinol and pyrogallol interference on the detection of CC and HQ and results showed that they were affecting slightly the peak currents.

10) Application of the Sensor Developed for the Detection of $C C$ and $H Q$ in Seawater: The differential pulse voltammetry method was applied to seawater samples for the quantification of catechol and hydroquinone. These samples were prepared with known amounts of CC and HQ. Quantitative analysis can be performed by DPV for the prepared samples. The calibration curve was used to determine the measured concentrations of HQ and CC. The results obtained for the samples are summarized in Table III. The obtained results show a concordance between the quantities injected and the quantities detected by the modified electrode. These results confirm the efficiency of our sensor for the quantification of HQ and CC molecules in real samples (Table III).

The recovery rates are in the range of 90 to $150 \%$ this indicates that the sensor needs further investigation in order to be used in real samples.

\section{CONCLUSiON}

The Ni nanoparticles and poly-4-nitroaniline were deposited on the surface of glassy carbon via electrochemical method and characterized by various techniques such as voltammetry, impedance spectroscopy, and UV spectroscopy. Further, the modified sensor was used for the detection of catechol and hydroquinone. Under optimized conditions, good sensitivity to catechol is obtained with a wide range of linearity. This led to testing this same electrode for the simultaneous detection of hydroquinone and catechol. Good sensitivity to catechol $(77 \mu \mathrm{A} / \mathrm{M})$ and hydroquinone $(56 \mu \mathrm{A} / \mathrm{M})$ is obtained compared to the literature with a wide range of linearity from $5.10^{-6} \mathrm{M}$ to $10^{-3} \mathrm{M}$.

\section{References}

[1] J. Wang, J.-N. Park, X.-Y. Wei, and C. W. Lee, "Room-temperature heterogeneous hydroxylation of phenol with hydrogen peroxide over $\mathrm{Fe}^{2+}, \mathrm{Co}^{2+}$ ion-exchanged na $\beta$ zeolite," Chem. Commun., no. 5, pp. 628-629, Feb. 2003.

[2] Y. Zhang, S. Xiao, J. Xie, Z. Yang, P. Pang, and Y. Gao, "Simultaneous electrochemical determination of catechol and hydroquinone based on graphene- $\mathrm{TiO}_{2}$ nanocomposite modified glassy carbon electrode," Sens. Actuators B, Chem., vol. 204, pp. 102-108, Dec. 2014.

[3] H. Zhou et al., "Copper nanoparticles modified nitrogen doped reduced graphene oxide 3-D superstructure for simultaneous determination of dihydroxybenzene isomers," Sens. Actuators B, Chem., vol. 249, pp. 405-413, Oct. 2017.

[4] L.-H. Wang and Y.-P. Kuo, "Simultaneous quantitative determination of resorcinol and 1-naphthol in haircolor products by high-performance liquid chromatography," Chromatographia, vol. 49, nos. 3-4, pp. 208-211, Feb. 1999.

[5] P. Nagaraja, R. A. Vasantha, and K. R. Sunitha, "A new sensitive and selective spectrophotometric method for the determination of catechol derivatives and its pharmaceutical preparations," J. Pharmaceutical Biomed. Anal., vol. 25, nos. 3-4, pp. 417-424, Jun. 2001.

[6] Y. Sun, "Determination of some catechol derivatives by a flow injection electrochemiluminescent inhibition method," Talanta, vol. 53, no. 3 , pp. 661-666, Dec. 2000.

[7] H. Cui, C. He, and G. Zhao, "Determination of polyphenols by high-performance liquid chromatography with inhibited chemiluminescence detection," J. Chromatography A, vol. 855, no. 1, pp. 171-179, Sep. 1999.

[8] E. Bakker and M. Telting-Diaz, "Electrochemical sensors," Anal. Chem., vol. 74, no. 12, pp. 2781-2800, 2002.

[9] W. Liu et al., "Nanopore array derived from 1-cysteine oxide/gold hybrids: Enhanced sensing platform for hydroquinone and catechol determination," Electrochim. Acta, vol. 88, pp. 15-23, Jan. 2013.

[10] M. Amiri, S. Ghaffari, A. Bezaatpour, and F. Marken, "Carbon nanoparticle-chitosan composite electrode with anion, cation, and neutral binding sites: Dihydroxybenzene selectivity," Sens. Actuators B, Chem., vol. 162, no. 1, pp. 194-200, Feb. 2012.

[11] Q. Guo, J. Huang, P. Chen, Y. Liu, H. Hou, and T. You, "Simultaneous determination of catechol and hydroquinone using electrospun carbon nanofibers modified electrode," Sens. Actuators B, Chem., vol. 163, no. 1, pp. 179-185, Mar. 2012.

[12] H. Qi and C. Zhang, "Simultaneous determination of hydroquinone and catechol at a glassy carbon electrode modified with multiwall carbon nanotubes," Electroanalysis, vol. 17, no. 10, pp. 832-838, May 2005.

[13] X. Feng, W. Gao, S. Zhou, H. Shi, H. Huang, and W. Song, "Discrimination and simultaneous determination of hydroquinone and catechol by tunable polymerization of imidazolium-based ionic liquid on multiwalled carbon nanotube surfaces," Analytica Chim. Acta, vol. 805, pp. 36-44, Dec. 2013.

[14] H. Du, J. Ye, J. Zhang, X. Huang, and C. Yu, "A voltammetric sensor based on graphene-modified electrode for simultaneous determination of catechol and hydroquinone," J. Electroanal. Chem., vol. 650, no. 2, pp. 209-213, Jan. 2011.

[15] S. Darvishi, F. Karmizadeh, and M. Kharaziha, "A facile one-step electrochemical synthesis of nickel nanoparticle/graphene composites for non-enzymatic biosensor applications," Procedia Mater. Sci., vol. 11, pp. 142-146, Jan. 2015.

[16] L. Jiang, S. Gu, Y. Ding, F. Jiang, and Z. Zhang, "Facile and novel electrochemical preparation of a graphene-transition metal oxide nanocomposite for ultrasensitive electrochemical sensing of acetaminophen and phenacetin," Nanoscale, vol. 6, no. 1, pp. 207-214, 2014.

[17] A. Yakoh, C. Pinyorospathum, W. Siangproh, and O. Chailapakul, "Biomedical probes based on inorganic nanoparticles for electrochemical and optical spectroscopy applications," Sensors, vol. 15, no. 9, pp. 21427-21477, Aug. 2015. 
[18] A. Maringa, T. Mugadza, E. Antunes, and T. Nyokong, "Characterization and electrocatalytic behaviour of glassy carbon electrode modified with nickel nanoparticles towards amitrole detection," J. Electroanal. Chem., vol. 700, pp. 86-92, Jul. 2013.

[19] A. A. Ensafi, B. Arashpour, B. Rezaei, and A. R. Allafchian, "Voltammetric behavior of dopamine at a glassy carbon electrode modified with $\mathrm{NiFe}_{2} \mathrm{O}_{4}$ magnetic nanoparticles decorated with multiwall carbon nanotubes," Mater. Sci. Eng. C., vol. 39, pp. 78-80, 2014.

[20] X.-S. Li, G.-T. Zhu, Y.-B. Luo, B.-F. Yuan, and Y.-Q. Feng, "Synthesis and applications of functionalized magnetic materials in sample preparation," TrAC Trends Anal. Chem., vol. 45, pp. 233-247, Apr. 2013.

[21] Y. Moliner-Martínez, A. Ribera, E. Coronado, and P. Campíns-Falcó, "Preconcentration of emerging contaminants in environmental water samples by using silica supported $\mathrm{Fe}_{3} \mathrm{O}_{4}$ magnetic nanoparticles for improving mass detection in capillary liquid chromatography," J. Chromatography A, vol. 1218, no. 16, pp. 2276-2283, Apr. 2011.

[22] L. Chen, T. Wang, and J. Tong, "Application of derivatized magnetic materials to the separation and the preconcentration of pollutants in water samples," TrAC Trends Anal. Chem., vol. 30, no. 7, pp. 1095-1108, Jul. 2011

[23] S. C. N. Tang and I. M. C. Lo, "Magnetic nanoparticles: Essential factors for sustainable environmental applications," Water Res., vol. 47, no. 8 , pp. 2613-2632, May 2013

[24] R. D. Ambashta and M. Sillanpää, "Water purification using magnetic assistance: A review," J. Hazardous Mater, vol. 180, nos. 1-3, pp. 38-49, Aug. 2010.

[25] J. K. Oh and J. M. Park, "Iron oxide-based superparamagnetic polymeric nanomaterials: Design, preparation, and biomedical application," Prog. Polym. Sci., vol. 36, no. 1, pp. 168-189, Jan. 2011.

[26] M. Colombo, "Biological applications of magnetic nanoparticles," Chem. Soc. Rev., vol. 41, no. 11, pp. 4306-4334, 2012.

[27] S.-H. Huang and R.-S. Juang, "Biochemical and biomedical applications of multifunctional magnetic nanoparticles: A review," J. Nanoparticle Res., vol. 13, no. 10, pp. 4411-4430, Oct. 2011.

[28] K. Aguilar-Arteaga, J. A. Rodriguez, and E. Barrado, "Magnetic solids in analytical chemistry: A review," Analytica Chim. Acta, vol. 674, no. 2 , pp. 157-165, Aug. 2010.

[29] J. S. Beveridge, J. R. Stephens, and M. E. Williams, "The use of magnetic nanoparticles in analytical chemistry," Annи. Rev. Anal. Chem., vol. 4, no. 1, pp. 251-273, Jul. 2011.

[30] S. C. Romero, "Muliplexed sensing and imaging with colloidal nanoand microparticles," Аnnu. Rev. Anal. Chem., vol. 6, pp. 53-81, Jun. 2013.

[31] M. Iranifam, "Analytical applications of chemiluminescence-detection systems assisted by magnetic microparticles and nanoparticles," TrAC Trends Anal. Chem., vol. 51, pp. 51-70, Nov. 2013.

[32] Y. Xu and E. Wang, "Electrochemical biosensors based on magnetic micro/nanoparticles," Electrochim. Acta., vol. 84, pp. 62-73, 2012.

[33] T. A. P. Rocha-Santos, "Sensors and biosensors based on magnetic nanoparticles," TrAC Trends Anal. Chem., vol. 62, pp. 28-36, Nov. 2014.

[34] C. Ben Ali Hassine and H. Barhoumi, "Electrochemical study of a glassy carbon electrode modified by poly-4-nitroaniline-reduced/murexide and its sensitivity for metal ions," Anal. Biochem., vol. 560, pp. 30-38, Nov. 2018.

[35] C. Ben Ali Hassine, M. Bourourou, H. Barhoumi, and N. Jaffrezic, "Copper(II) electrochemical sensor based on aluminon as chelating ionophore," IEEE Sensors J., vol. 19, no. 19, pp. 8605-8611, Oct. 2019.

[36] X. Niu, M. Lan, H. Zhao, and C. Chen, "Highly sensitive and selective nonenzymatic detection of glucose using three-dimensional porous nickel nanostructures," Anal. Chem., vol. 85, no. 7, pp. 3561-3569, Apr. 2013.

[37] C.-Y. Chiu, P.-J. Chung, K.-U. Lao, C.-W. Liao, and M. H. Huang, "Facet-dependent catalytic activity of gold nanocubes, octahedra, and rhombic dodecahedra toward 4-nitroaniline reduction," J. Phys. Chem. C, vol. 116, no. 44, pp. 23757-23763, Nov. 2012.

[38] J. Arjomandi, H. Makhdomi, and M. H. Parvin, "Novel conducting poly (p-nitro aniline-co-N-methyl aniline): Electrosynthesis, mechanism and in situ spectroelectrochemical characterization," Synth. Met., vol. 220, pp. 123-133, Oct. 2016.

[39] N. Aravindan and M. V. Sangaranarayanan, "Differential pulse voltammetry as an alternate technique for over oxidation of polymers: Application of electrochemically synthesized over oxidized poly (Alizarin Red S) modified disposable pencil graphite electrodes for simultaneous detection of hydroquinone and catechol," J. Electroanal. Chem., vol. 789, pp. 148-159, Mar. 2017.
[40] L. Zhao et al., "Nickel oxide/carbon nanotube nanocomposites prepared by atomic layer deposition for electrochemical sensing of hydroquinone and catechol," J. Electroanal. Chem., vol. 808, pp. 245-251, Jan. 2018.

[41] Y. Chen et al., "Ultrasensitive and simultaneous detection of hydroquinone, catechol and resorcinol based on the electrochemical co-reduction prepared Au-Pd nanoflower/reduced graphene oxide nanocomposite," Electrochim. Acta, vol. 231, pp. 677-685, Mar. 2017.

[42] J. Tashkhourian, M. Daneshi, F. Nami-Ana, M. Behbahani, and A. Bagheri, "Simultaneous determination of hydroquinone and catechol at gold nanoparticles mesoporous silica modified carbon paste electrode," J. Hazardous Mater, vol. 318, pp. 117-124, Nov. 2016.

[43] H. Wang, S. Zhang, S. Li, and J. Qu, "Simultaneous determination of hydroquinone and catechol using a glassy carbon electrode modified with Au@Pd loaded on reduced graphene oxide," Anal. Methods, vol. 10, no. 11, pp. 1331-1338, 2018.

[44] Z. Huo, Y. Zhou, Q. Liu, X. He, Y. Liang, and M. Xu, "Sensitive simultaneous determination of catechol and hydroquinone using a gold electrode modified with carbon nanofibers and gold nanoparticles," Microchim. Acta, vol. 173, nos. 1-2, pp. 119-125, Apr. 2011.

[45] A. J. S. Ahammad, S. Sarker, M. A. Rahman, and J.-J. Lee, "Simultaneous determination of hydroquinone and catechol at an activated glassy carbon electrode," Electroanalysis, vol. 22, no. 6, pp. 694-700, Mar. 2010.

[46] J. Wang, Analytical Electrochemistry, 3rd ed. Hoboken, NJ, USA: Wiley, 2006, pp. 30-33.

[47] X. Zheng et al., "Electrochemical detection of hydroquinone and catechol with covalent organic framework modified carbon paste electrode," J. Electroanal. Chem., vol. 877, pp. 114-530, Nov. 2020.

[48] X. Zheng et al., "N-doped carbon nanotube frameworks modified electrode for the selective sensing of hydroquinone and catechol," J. Electroanal. Chem., vol. 861, Mar. 2020, Art. no. 113968.

[49] Ç. C. Koçak and S. Koçak, "Enhanced electrochemical determination of catechol and hydroquinone based on Pd nanoparticles/poly(taurine) modified glassy carbon electrode," Electroanalysis, vol. 32, no. 2, pp. 358-366, Feb. 2020.

[50] S. U. Karabiberoglu, Ç. C. Koçak, and Z. Dursun, "An over-oxidized poly(Rutin) modified electrode for selective and sensitive determination of catechol and hydroquinone," J. Electroanal. Chem., vol. 850, pp. 113-415, Oct. 2019.

[51] S. Koçak, "Platinum nanoparticles/poly(isoleucine) modified glassy carbon electrode for the simultaneous determination of hydroquinone and catechol," Electroanalysis, vol. 33, no. 2, pp. 375-382, Feb. 2021.

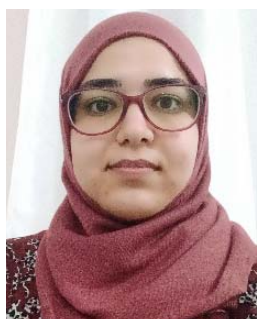

Chedia Ben Ali Hassine received the bachelor's and master's degrees in chemistry and the Ph.D. degree from the Faculty of Science, University of Monastir, Tunisia, in 2011, 2013, and 2018, respectively. Her research focuses on the development and characterization of hybrid nanocomposites based on nanoparticles and conductive polymers and their application to electrochemical sensors.

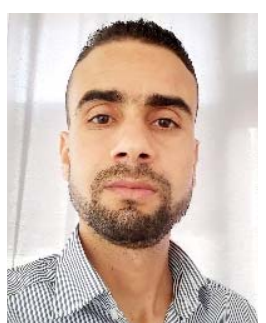

Hamza Kahri was born in Bizerte, Tunisia, in 1989. He received the Ph.D. degree from co-ordination between the University of Montpellier, Montpellier, France, and the University of Monastir, Monastir, Tunisia, in 2017. He is a Researcher with Bilkent University, Ankara, Turkey. His recent research interests include electrochemistry, photocatalysis, nanomaterials synthesis and applications, heterogeneous catalysis, and mesoporous material synthesis.

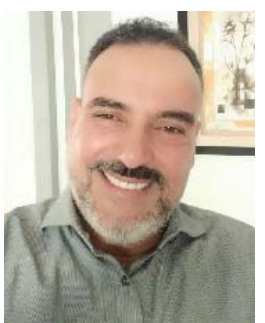

Houcine Barhoumi was born in Jendouba, North of Tunisia, in 1972. He received the Ph.D. degree in physical chemistry in 2006 and the Habilitation degree in 2015. He is currently a Researcher and a Professor with the Department of Chemistry, University of Monastir, Tunisia. His researches involve the surface and interface electrochemical optimization for electrochemical sensors development for ions and bioanalyte quantification, and the fabrication of multi-sensors called electronic tongue for the 